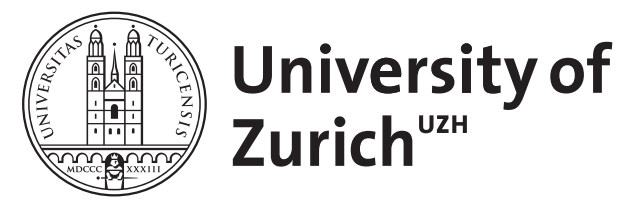

\title{
Sleep enhances exposure therapy
}

Kleim, Birgit ; Wilhelm, F H ; Temp, L ; Margraf, J ; Wiederhold, B K ; Rasch, Björn

\begin{abstract}
Background: Sleep benefits memory consolidation. Here, we tested the beneficial effect of sleep on memory consolidation following exposure psychotherapy of phobic anxiety. Method: A total of 40 individuals afflicted with spider phobia according to DSM-IV underwent a one-session virtual reality exposure treatment and either slept for $90 \mathrm{~min}$ or stayed awake afterwards. Results: Sleep following exposure therapy compared with wakefulness led to better reductions in self-reported fear ( $\mathrm{p}$ $=0.045, \mathrm{~d}=0.47)$ and catastrophic spider-related cognitions $(\mathrm{p}=0.026, \mathrm{~d}=0.53)$ during approaching a live spider, both tested after 1 week. Both reductions were associated with greater percentages of stage 2 sleep. Conclusions: Our results indicate that sleep following successful psychotherapy, such as exposure therapy, improves therapeutic effectiveness, possibly by strengthening new non-fearful memory traces established during therapy. These findings offer an important non-invasive alternative to recent attempts to facilitate therapeutic memory extinction and consolidation processes with pharmacological or behavioral interventions.
\end{abstract}

DOI: https://doi.org/10.1017/S0033291713001748

Posted at the Zurich Open Repository and Archive, University of Zurich ZORA URL: https://doi.org/10.5167/uzh-90519

Journal Article

Published Version

Originally published at:

Kleim, Birgit; Wilhelm, F H; Temp, L; Margraf, J; Wiederhold, B K; Rasch, Björn (2014). Sleep enhances exposure therapy. Psychological Medicine, 44(07):1511-1519.

DOI: https://doi.org/10.1017/S0033291713001748 


\section{Psychological Medicine}

http://journals.cambridge.org/PSM

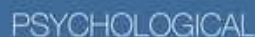

Additional services for Psychological Medicine:

Email alerts: Click here

Subscriptions: Click here

Commercial reprints: Click here

Terms of use : $\underline{\text { Click here }}$

\section{Sleep enhances exposure therapy}

B. Kleim, F. H. Wilhelm, L. Temp, J. Margraf, B. K. Wiederhold and B. Rasch

Psychological Medicine / FirstView Article / January 2014, pp 1 - 9

DOI: 10.1017/S0033291713001748, Published online: 10 July 2013

Link to this article: http://journals.cambridge.org/abstract_S0033291713001748

How to cite this article:

B. Kleim, F. H. Wilhelm, L. Temp, J. Margraf, B. K. Wiederhold and B. Rasch Sleep enhances exposure therapy.

Psychological Medicine, Available on CJO 2013 doi:10.1017/S0033291713001748

Request Permissions : $\underline{\text { Click here }}$ 


\title{
Sleep enhances exposure therapy
}

\author{
B. Kleim ${ }^{1 *}$, F. H. Wilhelm ${ }^{2}$, L. Temp ${ }^{3}$, J. Margraf ${ }^{4}$, B. K. Wiederhold ${ }^{5,6}$ and B. Rasch ${ }^{7}$ \\ ${ }^{1}$ Department of Clinical Psychology and Psychotherapy, University of Zurich, Zurich, Switzerland \\ ${ }^{2}$ Department of Clinical Psychology, Psychotherapy, and Health Psychology, University of Salzburg, Salzburg, Austria \\ ${ }^{3}$ University of Basel, Basel, Switzerland \\ ${ }^{4}$ Center for the Study and Treatment of Mental Health, Department of Clinical Psychology, Ruhr-University Bochum, Germany \\ ${ }^{5}$ Virtual Reality Medical Center, San Diego, CA, USA \\ ${ }^{6}$ Virtual Reality Medical Center, Brussels, Belgium \\ ${ }^{7}$ Department of Biopsychology, University of Zurich, Zurich, Switzerland
}

Background. Sleep benefits memory consolidation. Here, we tested the beneficial effect of sleep on memory consolidation following exposure psychotherapy of phobic anxiety.

Method. A total of 40 individuals afflicted with spider phobia according to DSM-IV underwent a one-session virtual reality exposure treatment and either slept for $90 \mathrm{~min}$ or stayed awake afterwards.

Results. Sleep following exposure therapy compared with wakefulness led to better reductions in self-reported fear $(p=0.045, d=0.47)$ and catastrophic spider-related cognitions $(p=0.026, d=0.53)$ during approaching a live spider, both tested after 1 week. Both reductions were associated with greater percentages of stage 2 sleep.

Conclusions. Our results indicate that sleep following successful psychotherapy, such as exposure therapy, improves therapeutic effectiveness, possibly by strengthening new non-fearful memory traces established during therapy. These findings offer an important non-invasive alternative to recent attempts to facilitate therapeutic memory extinction and consolidation processes with pharmacological or behavioral interventions.

Received 4 October 2012; Revised 20 June 2013; Accepted 20 June 2013

Key words: Electroencephalography, emotional learning, exposure therapy, memory consolidation, phobia, sleep.

\section{Introduction}

Sleep benefits emotional learning in various tasks, such as learning negative memories (Pace-Schott et al. 2009), habituation to emotional stimuli (Pace-Schott et al. 2011), or retention of previously encoded emotional pictures or texts (Wagner et al. 2001; Payne et al. 2008; Nishida et al. 2009). Effects of a 3-h nap following emotional learning are even detectable 4 years later (Wagner et al. 2006). In addition to strengthening of the content of the emotional memory, sleep plays an important role in reducing the degree of emotional arousal associated with the memory (Walker \& van der Helm, 2009; Pace-Schott et al. 2011; van der Helm et al. 2011b). Collectively, these studies indicate that sleep plays an important role in modulation and integration of emotional memories (Walker, 2008, 2009; Wamsley \& Stickgold, 2010). More specifically, sleepdependent memory processing relies on an offline reactivation and consolidation during which new and

\footnotetext{
* Address for correspondence: B. Kleim, Ph.D., Department of Clinical Psychology and Psychotherapy, University of Zurich, Binzmühlestrasse 14, Box 26, CH-8050 Zurich, Switzerland.

(Email: b.kleim@psychologie.uzh.ch)
}

initially labile memories encoded during wakefulness are transformed into more stable representations and gradually integrated in cortical networks of preexisting long-term memories (Diekelmann \& Born, 2010). Significant effects of sleep on memory occur after naps of 1-2 h (Mednick et al. 2003; Diekelmann et al. 2009), and even after ultra-short naps of $6 \mathrm{~min}$ (Lahl et al. 2008; Nishida et al. 2009). A recent study demonstrated significant memory enhancements following a 90-min, but not following a shorter 40-min sleep interval compared with wakefulness (Diekelmann et al. 2012). Concerning sleep stage contributions, non-rapid eye movement sleep is associated with the strengthening of hippocampus-dependent declarative memories (Stickgold, 2009), whereas rapid eye movement (REM) sleep has been implicated in the modulation of emotional memories and arousal (Walker \& van der Helm, 2009; van der Helm et al. $2011 b$ ) and the extinction of conditioned fear (Spoormaker et al. 2010, 2011).

Here, we test the beneficial effect of sleep on memory consolidation following treatment of phobic anxiety with exposure therapy. Exposure therapy is a prime exemplar of a learning situation during which new memory traces are formed that need to be 


\section{B. Kleim et al.}

consolidated and integrated with pre-existing memories and experiences. It has consistently been shown to be effective in the treatment of phobia, which represents one of the most frequent types of mental disorders (Magee et al. 1996; Ruhmland \& Margraf, 2001; Choy, 2007; Norton \& Price, 2007). However, some patients do not respond to this form of treatment, achieve only partial symptom remission, or fear often returns following initially successful therapy (Mystkowski et al. 2002, 2006; Craske \& Mystkowski, 2006). Consequently, the development of novel and innovative approaches to increase therapeutic effectiveness is a primary challenge in current research on treatment of anxiety disorders (Ressler et al. 2004; McNally, 2007; De Quervain, 2011).

One promising candidate for enhancing therapeutic effectiveness is sleep and its potential beneficial influence on memory formation. There is now preliminary evidence that a period of sleep following a simulated version of exposure therapy may promote retention and generalization of extinction learning in individuals with phobic anxiety (Pace-Schott et al. 2012). To the best of our knowledge, the current study is the first to extend the result of sleep-induced memory consolidation to a clinical context of patients afflicted with specific phobia according to the Diagnostic and Statistical Manual of Mental Disorders; Fourth Edition (DSM-IV; APA, 1994) employing a one-session virtual exposure therapy. We treated 40 patients with one-session virtual exposure to spiders. Virtual reality (VR) treatment of phobias effectively reduces phobic fear (Emmelkamp et al. 2001; Powers \& Emmelkamp, 2008; Wamsley \& Stickgold, 2010), and previous studies indicate that 1-day exposure sessions may be sufficient in order to markedly reduce phobic fear (Ost, 1996; Ost et al. 1997). In concordance with the hypothesized role of sleep in offline consolidation of emotional memories, we hypothesized that sleep following an exposure therapy session compared with wakefulness leads to greater reductions in subjective anxiety and catastrophic spider-related cognitions, as well as greater increases in behavioral approach towards a live spider.

\section{Method}

\section{Subjects}

Inclusion criteria were a diagnosis of specific phobia according to DSM-IV (APA, 1994), including a subjective interference score of at least 3 out of $10(0=$ not at all interfering; $10=$ extremely interfering), no current sleep problems, and no alcohol or drug dependence. Of 80 subjects recruited via newspaper advertisements, 20 failed to meet these inclusion criteria, six chose not to participate, and four wished to discontinue following the initial assessment. A total of 50 individuals underwent the one-session VR exposure treatment. Of these, however, five produced a faulty electroencephalogram (EEG) signal and could not be included as sleep was not recorded, two subjects did not return for any follow-up, and three subjects were excluded following an outlier analysis indicating implausible questionnaire scores. Data from 40 subjects were included in the analyses. Subjects received 50 Swiss francs (approximately US\$55) as compensation for their participation.

\section{Procedure}

The ethics committee of the University of Basel approved the study. Participation included three appointments: an initial screening session to assess phobia symptoms, absence of depression, psychosis and sleep-related variables, including medication intake that could interfere with sleep, and behavioral approach towards a live spider before treatment (pretreatment assessment), a single VR exposure treatment session (treatment), and an assessment at the laboratory 7 days following treatment (1-week follow-up). Pre-treatment assessments took place at the laboratory 1 week prior to the scheduled exposure session. After describing the study to participants, written informed consent was obtained. Participants then completed a structured clinical interview in order to assess whether they fulfilled diagnostic criteria for specific phobia and performed a behavioral approach task (BAT, see Mystkowski et al. 2002). During the BAT, they were asked to approach a caged tarantula. The widely used measure of self-reported fear, the Subjective Units of Distress Scale (SUDS; Wolpe, 1966) was used. This was a 100-point scale on which participants rated their level of fear/anxiety. Using the same scale, they rated the severity of their personal most catastrophic spider-related cognition. A behavioral avoidance measurement, i.e. closest distance in $\mathrm{cm}$ to a spider, was also taken. In addition, participants filled in questionnaires, and were then all set up for a 45-min nap in the laboratory in order to get accustomed to the laboratory setting. Before they left, they received some psychoeducative material, i.e. a short description about exposure therapy.

\section{VR exposure therapy session}

Exposure treatments took place at a standardized time for all participants (12.15 hours) in a temperaturecontrolled, sound-attenuated and darkened room connected to an adjoining control room. Prior to the session, physiological sensors, head-mounted display and headphones were adjusted. Via the display, 
participants were exposed to spiders in a VR environment (Virtual Reality Medical Center, San Diego, CA, USA) that was simulated by a computer program. A sensor registered head movements and altered the display to reproduce a change in gaze direction. The therapist controlled the treatment via a computer in the control room and adapted a standardized therapy protocol depending on each participant's strength of self-reported fear. Participants were guided through a VR environment with different rooms of an apartment that contained various spiders. They were systematically guided through the environment and had to pass the same predefined locations. Participants were instructed to move their heads and look around at various points. They started the exposure session by entering the virtual apartment. Participants stayed in a given location for $60 \mathrm{~s}$, or until their SUDS, taken every $30 \mathrm{~s}$, were reduced by $20 \%$. A maximum of 13 stations was available and participants spent a total of $45 \mathrm{~min}$ in the virtual environment. This highly standardized exposure protocol was similar to the one used in a study of VR exposure in height phobia (De Quervain et al. 2011).

Following the exposure session, participants were randomly assigned by a pre-generated list of random assignments to either sleep or wake condition by a third person blind to therapy procedures and outcome. These experimental groups differed marginally in their spider phobia severity, and there were no differences in trait anxiety or depression. They were then set up to either sleep (sleep group) or to watch a neutral video (documentary of European Cities by The National Geographic Society, wake group), both for 90 min (see Diekelmann et al. 2012), in a different room at the laboratory. Finally, all participants completed a BAT approximately $5 \mathrm{~min}$ following the sleep period or watching the neutral video, respectively.

\section{Follow-up assessment}

Patients returned to the laboratory 1 week following the exposure session, where they completed another BAT and filled in questionnaires.

\section{Sleep recordings}

Sleep was recorded using a portable EEG machine (SOMNOscreen EEG 10/20; SOMNOmedics, Germany). EEG was recorded for $90 \mathrm{~min}$ in both conditions (sleep, wake) on $\mathrm{Fz}, \mathrm{Cz}, \mathrm{Pz}$ and $\mathrm{Oz}$ channels according to the international $10 / 20$ system. Sleep parameters and architecture were determined using a validated automatic scoring algorithm (Anderer et al. 2010) according to standard criteria of the American Association of Sleep Medicine. EEG recordings were examined individually to assess the occurrence of sleep during both conditions.

Sleep recordings revealed that only one participant fell asleep in the video control group (time in stage N2 sleep: $11 \mathrm{~min}$ ), and he was transferred to the sleep group. In the sleep group, two subjects were unable to reach stable sleep for more than $5 \mathrm{~min}$ (time in stage N2 sleep: 1 and $3 \mathrm{~min}$, respectively), and they were transferred to the wake group. Thus, in our analysis, the sleep group consisted of 21 participants (18 female, three male participants) and the wake group consisted of 19 participants (16 female, three male participants). The groups did not differ significantly in terms of age, sex and other demographic and clinical characteristics, including trait anxiety, depression and initial behavioral approach scores (all $p>0.20$, see Table 1). There was a marginal difference in initial severity of phobia symptoms $(p=0.093)$. Importantly, there were no significant group differences in self-reported exposure to spiders in participants' everyday lives during the follow-up period, neither in frequency of any spider exposure $(p=0.430)$ nor in active exposure seeking $(p=0.635)$.

\section{Interview and questionnaire measures}

Diagnostic criteria for specific phobia were assessed by graduate-level clinical psychologists using a structured Diagnostic Interview for Mental Disorders (DIPS; Schneider \& Margraf, 2006). The DIPS is a reliable interview, with good construct validity (Suppiger et al. 2008). It is based on a German translation and extension of the Anxiety Disorders Interview Schedule for DSM-IV, and is designed to assess the most relevant mental disorders according to DSM-IV, text revision (DSM-IV-TR). A sum score was calculated indexing phobia severity. This score summed answers to questions on subjective spider anxiety, physiological arousal, avoidance, and interference with respect to spider anxiety. The following selfreport questionnaires were administered: chronotype was assessed with the German version of the Morningness-Eveningness Questionnaire (Horne \& Ostberg, 1976); excessive daytime sleepiness was assessed using the Epworth Sleepiness Scale (Johns, 1994); and sleep quality was assessed using the Pittsburgh Sleep Quality Index (Buysse et al. 1989). The Spider Phobia Beliefs Questionnaire (Arntz et al. 1993) assessed catastrophic spider-related cognitions (e.g. 'The spider is deadly', or 'The spider will attack me'). Depressive symptoms were assessed with the Beck Depression Inventory (BDI-II; Beck \& Steer, 1987). Presence in the virtual environment, i.e. the level of connection an individual feels with the virtual environment, is a critical construct for the experience of 
Table 1. Pre-treatment sociodemographic, clinical and sleep characteristics of the sleep versus the wake group

\begin{tabular}{|c|c|c|c|}
\hline Variable & $\begin{array}{l}\text { Sleep group } \\
(n=21)\end{array}$ & $\begin{array}{l}\text { Wake group } \\
(n=19)\end{array}$ & Statistics \\
\hline Age, years & $25.81(6.96)$ & $27.63(9.77)$ & $F_{1,39}=0.47, p=0.498$ \\
\hline Sex, female, $n(\%)$ & $18(85.7)$ & $16(94.7)$ & $\chi_{1}^{2}=0.018, p=0.619$ \\
\hline Work, full/part-time work, $n(\%)$ & $18(85.7)$ & $18(85.7)$ & $\chi_{1}^{2}=1.05, p=0.788$ \\
\hline Alcohol, units per week & $3.18(3.26)$ & $2.93(2.49)$ & $F_{1,39}=0.06, p=0.816$ \\
\hline Smoking, no. cigarettes per week & $37.60(57.28)$ & $19.40(16.71)$ & $F_{1,39}=0.47, p=0.514$ \\
\hline Severity of phobia diagnosis ${ }^{a}$ & $5.24(1.84)$ & $4.00(1.64)$ & $F_{1,39}=3.11, p=0.093$ \\
\hline Trait anxiety & $47.38(2.22)$ & $47.32(2.24)$ & $F_{1,39}=0.10, p=0.927$ \\
\hline BDI-II score & $7.13(6.38)$ & $4.57(3.60)$ & $F_{1,39}=0.97, p=0.337$ \\
\hline Epworth Sleepiness Scale score & $9.57(3.11)$ & $8.16(3.78)$ & $F_{1,39}=1.68, p=0.202$ \\
\hline Pittsburgh Sleep Quality Index total score & $13.52(1.40)$ & $12.79(0.98)$ & $F_{1,39}=3.62, p=0.065$ \\
\hline \multicolumn{4}{|l|}{ Chronotype, $n(\%)^{\mathrm{b}}$} \\
\hline Morning type & $2(9.5)$ & $2(10.5)$ & \multirow[t]{3}{*}{$\chi^{2}=1.62, p=0.655$} \\
\hline Neutral type & $16(76.2)$ & $12(63.2)$ & \\
\hline Evening type & $2(9.5)$ & $5(26.3)$ & \\
\hline Total sleep time, min & $52.25(18.62)$ & $0.71(2.15)$ & $F_{1,39}=143.34, p<0.001$ \\
\hline Sleep stage N1, min & $10.17(5.51)$ & $0.42(1.30)$ & $F_{1,39}=56.45, p<0.001$ \\
\hline Sleep stage $\mathrm{N} 2$, min & 30.05 (12.05) & $0.24(0.75)$ & $F_{1,39}=115.59, p<0.001$ \\
\hline Slow-wave sleep, $\min$ & $12.55(14.06)$ & 0 & $U=47.50, p<0.001$ \\
\hline REM sleep, min & $1.52(3.18)$ & 0 & $U=135.00, p=0.015$ \\
\hline
\end{tabular}

Data are given as mean (standard deviation) unless otherwise indicated.

BDI, Beck Depression Inventory; REM, rapid eye movement.

${ }^{a}$ Phobia symptom severity from clinical interview.

${ }^{\mathrm{b}}$ Chronotype was assessed with the German version of the Morningness-Eveningness Questionnaire.

anxiety and for successful response to the VR (Price et al. 2011) and was assessed with the Immersive Tendencies Questionnaire (Scheuchenpflug, 2001).

\section{Statistical analysis}

Statistical analyses were performed with PASW 19.0 for Macintosh (SPSS Inc., USA). Group differences in demographic, clinical and sleep-related variables, and initial BAT scores were analysed with analysis of variance, $\chi^{2}$ or Mann-Whitney $U$ tests. Separate general linear models (GLM) were calculated as multivariate tests for repeated measures to assess the effect of group and time on BAT outcome variables (immediate and 1-week change scores in fear, cognition, avoidance), controlling for initial phobia severity and subjective presence in the virtual environment. In an explorative analysis, we correlated selected sleep indices with subjective anxiety and catastrophic cognition change scores. Effect sizes were calculated for significant results.

\section{Results}

\section{Effects of one-session VR exposure}

In the overall sample, we found a significant reduction of self-reported fear from pre- to post-exposure and 1-week follow-up assessment in several variables. First, subjective anxiety when approaching a live tarantula was reduced (SUDS rating, range 0-100): mean (S.D.) pre $=50.08$ (26.86) v. mean (S.D.) $)_{\text {post }}=25.17$ (22.61) $\left(F_{1,39}=39.94, p<0.001\right)$; mean (S.D. $)_{\text {follow-up }}=$ 20.08 (22.52) $\left(F_{1,39}=41.79, p<0.001, v\right.$. pre). The effect size from pre-treatment to post-treatment assessment was $d=1.01$, and from pre-treatment to follow-up was $d=1.22$. Spider-related negative beliefs, as measured during the BAT and by the Spider Phobia Beliefs Questionnaire significantly decreased during treatment: BAT - mean (S.D.) pre $=34.17$ (31.87) v. mean (S.D. $)_{\text {post }}=24.15$ (27.79) $\left(F_{1,39}=3.43, \quad p=0.071\right)$; mean (S.D. $)_{\text {follow-up }}=18.72 \quad(24.10) \quad\left(F_{1,39}=10.18, \quad p=0.003\right)$; questionnaire - mean (S.D.) $)_{\text {pre }}=20.64$ (3.96) $v$. mean (S.D. $)_{\text {follow-up }}=16.51(4.38)\left(F_{1,38}=39.94, p<0.001, d=1.0\right)$. Subjects also moved closer to the spider (distance to terrarium in $\mathrm{cm}$ ) from pre- to post-exposure: mean (S.D.) $)_{\text {pre }}=95.05$ (80.09) v. mean (S.D.) $)_{\text {post }}=51.10$ (48.06) $\left(F_{1,39}=33.61, \quad p<0.001, d=0.68\right)$, and to follow-up, mean (S.D.) $)_{\text {follow-up }}=39.30(48.83)\left(F_{1,39}=40.24, p<0.001\right.$, $d=0.87)$.

\section{Sleep following VR exposure}

Total sleep time during the assigned $90 \mathrm{~min}$ in the sleep group was $52.25 \mathrm{~min}$ (s.D. $=18.62 \mathrm{~min}$ ), with a 
Table 2. Initial self-reported fear, negative spider-related cognition and behavioral avoidance scores, and immediate and 1-week change scores ${ }^{\mathrm{a}}$

\begin{tabular}{lccc}
\hline Variable & Sleep group $(n=21)$ & Wake group $(n=19)$ & Statistics \\
\hline Initial baseline scores & & & \\
Self-reported fear & $51.33(26.07)$ & $48.68(28.34)$ & $F_{1,39}=1.00, p=0.760$ \\
Most threatening cognition & $35.00(34.86)$ & $33.26(29.14)$ & $F_{1,39}=0.03, p=0.866$ \\
Distance to spider, cm & $102.10(87.46)$ & $87.26(72.63)$ & $F_{1,39}=0.34, p=0.565$ \\
Immediate change scores & & & \\
Self-reported fear & $-24.29(23.98)$ & $-25.58(21.57)$ & $F_{1,39}=0.11, p=0.740$ \\
Most threatening cognition & $-5.67(36.34)$ & $-41.16(45.36)$ & $F_{1,39}=0.56, p=0.460$ \\
Distance to spider, cm & $-46.47(51.16)$ & & $F_{1,39}=0.39, p=0.535$ \\
1-week change scores & & $-0.63(14.84)$ & $F_{1,39}=4.30, p=0.045$ \\
Self-reported fear & $-9.14(21.10)$ & $+0.47(16.85)$ & $F_{1,39}=5.40, p=0.026$ \\
Most threatening cognition & $-10.76(18.94)$ & $-4.74(27.19)$ & $F_{1,39}=2.29, p=0.139$ \\
Distance to spider, cm & $-18.19(32.70)$ & &
\end{tabular}

Data are given as mean (standard deviation).

${ }^{a}$ Initial baseline scores were assessed 1 week prior to the exposure session. Immediate change scores were calculated by subtracting pre-exposure scores from immediate follow-up scores (assessed minutes after sleep/wake period); 1-week change scores were calculated by subtracting immediate follow-up scores from 1-week follow-up scores; ranges for fear and cognition scores were $0-100$.

mean sleep latency of $19.55 \mathrm{~min} \quad$ (S.D. $=9.81 \mathrm{~min}$ ). Average stage 2 sleep duration was $30.05 \mathrm{~min}$ (S.D.= $12.05 \mathrm{~min})$; average slow-wave sleep duration was $12.55 \mathrm{~min}$ (s.D. $=14.06 \mathrm{~min}$ ). Mean duration of REM sleep was $1.5 \mathrm{~min}$ (s.D. $=3.18 \mathrm{~min}$ ).

\section{Effects of sleep on VR exposure outcome}

The GLM testing the effect of group and time on fear change scores revealed a significant effect of time $\left(F_{1,36}=6.84, \quad p=0.013\right)$, with greater reductions at 1-week compared with immediate follow-up, as well as a significant interaction between group and time $\left(F_{1,36}=4.30, p=0.045\right)$. For cognition change scores, the GLM revealed a marginally significant effect of time $\left(F_{1,36}=3.22, p=0.081\right)$, and a significant interaction between group and time $\left(F_{1,36}=45.40, p=0.026\right)$. For behavioral avoidance, the effect of time was nonsignificant $(p=0.478)$, and the interaction between group and time was marginally significant $\left(F_{1,36}=\right.$ 2.29, $p=0.139)$. We followed up the significant interactions with post-hoc tests and found that sleep did not affect immediate changes in subjective anxiety, severity of catastrophic spider-related cognitions or distance in approaching a live tarantula (all $p$ values $>0.46$ ). However, with regard to the long-term effects, participants in the sleep group showed a stronger reduction in subjective anxiety from post-exposure assessment to follow-up assessment after 1-week as compared with the wake group; reduction scores: mean (S.D. $)_{\text {sleep }}=-9.14$ (21.10) $v$. mean (S.D. $)_{\text {wake }}=$ -0.63 (14.84) $\left(F_{1,36}=4.30, p=0.045, d=0.47\right)$. The sleep group also showed greater reductions in catastrophic cognitions at follow-up compared with post-exposure; reduction scores: mean (S.D.) $)_{\text {sleep }}=-10.76$ (18.94) v. mean (S.D.) $)_{\text {wake }}=0.47$ (16.85) $\left(F_{1,36}=5.40, p=0.026\right.$, $d=0.53$ ). The reduction in approach to the live spider (cm) was marginally significant; reduction scores: mean (S.D.) $)_{\text {sleep }}=-18.19$ (32.70) v. mean (S.D. $)_{\text {wake }}=$ $-4.74(27.19)\left(F_{1,36}=2.29, p=0.139\right)$. Initial scores, as well as immediate and 1-week change scores and tests for group differences, are reported in Table 2. Reductions of subjective anxiety and catastrophic spider-related cognitions for the sleep versus the wake group are displayed in Fig. 1.

The difference between changes in subjective anxiety and negative cognition was not significantly different in either group (all $p$ values $>0.770$ ). Neither sleep quality, as indexed by the Pittsburgh Sleep Quality Score, nor level of immersion in the VR setting was significantly related to any of the outcome scores (all $p$ values $>0.210)$.

\section{Sleep indices and VR exposure outcome}

In an exploratory analysis, contributions of sleep stage 2, slow-wave sleep and REM sleep to long-term reductions in self-reported fear and catastrophic cognitions in the BAT (change score from post-exposure to follow-up assessment) were investigated. Those with greater reduction in self-reported fear from post- to follow-up assessment had greater percentages of stage 2 sleep, again controlling for phobia severity and presence in the VR environment $(r=0.35, p=$ 0.03). Reduction of catastrophic cognitions was also related to more stage 2 sleep $(r=0.41, p=0.016)$. 


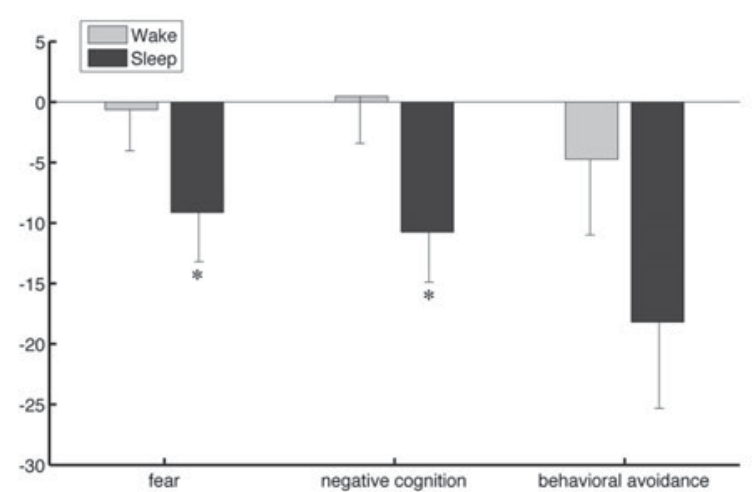

Fig. 1. Enhanced reduction in self-reported fear (range 0-100), fear-related negative cognition (range 0-100) and behavioral avoidance (distance to a spider in $\mathrm{cm}$ ) in the sleep compared with the wake group. The 1-week change scores were calculated by subtracting immediate follow-up scores from 1-week follow-up scores. Values are means, with standard errors represented by vertical bars. ${ }^{*}$ Mean value was significantly different from that for the wake group $(p<0.05)$.

There was no significant correlation between percentage of slow-wave sleep or REM sleep with change in self-reported fear and catastrophic cognitions (all $p>0.12$ ).

\section{Discussion}

It is generally established that sleep after learning benefits memory consolidation, but this knowledge has not yet been applied to the context of emotional learning in psychotherapy. Here we show that sleep after VR exposure therapy improves the therapeutic effectiveness in spider phobia. Patients who napped after exposure therapy showed greater reductions in subjective anxiety and catastrophic spider-related cognitions at follow-up testing (after 1 week) as compared with patients who stayed awake after the therapeutic intervention. No differences were observed immediately after sleep or waking. The enhancing effects of sleep after 1 week correlated with greater percentages of stage 2 sleep, pointing to the importance of stage 2 sleep for this type of memory consolidation.

To our knowledge, this is the first empirical test of whether and how patients are able to sleep immediately following exposure therapy. Exposure sessions tend to have substantial anxious arousal properties, so that it might have been expected that sustained arousal would prevent individuals from falling asleep after therapy. Our results demonstrate that this was not the case: mean sleep onset latency was around $20 \mathrm{~min}$, and individuals slept $50 \mathrm{~min}$ on average during the assigned 90-min period just after the exposure session. It is conceivable that our specific session format was strenuous and thus tiring for participants. Concentration on the head-mounted VR display may have contributed to this effect. Nevertheless, our findings clearly warrant further investigation of the effects of post-therapy sleep for all kinds of different therapeutic settings.

The most crucial finding of our study was that sleep facilitated the effects of exposure therapy in the long run. Not only did participants who slept show less fear at 1-week follow-up, they also reported a greater drop in their most severe spider-related cognition compared with those who remained awake. In contrast, the wake group did not show any reduction in these indices following the post-exposure measurement.

Exposure-based psychotherapy of phobia is thought to rely on extinction of fear responses (Ressler et al. 2004; McNally, 2007), a learning mechanism that has been shown to be significantly delayed in phobias and other anxiety disorders. In animals, the important role of sleep for extinction learning is well established. In honeybees, sleep after extinction learning improved extinction memory as compared with sleep deprivation (Hussaini et al. 2009). Similarly in rats, particularly REM sleep deprivation after extinction learning had an impairing effect on extinction (Silvestri et al. 2001; Silvestri \& Root, 2008). Also in humans, REM sleep deprivation increased skin conductance responses to previously extinguished fear cues (Spoormaker et al. 2011). In addition, undisturbed sleep after extinction learning (compared with wakefulness) in a classical conditioning paradigm promoted the generalization of extinction of conditioned fear, but did not directly affect extinction recall tested immediately after a sleep or waking interval (Pace-Schott et al. 2009). The lack of immediate effects of sleep or waking after extinction learning on extinction recall is consistent with the results of the current study and might be partly due to after-effects of prior sleep or wakefulness on emotional reactivity during the testing and recall phase (van der Helm et al. 2011a; van der Helm \& Walker, 2011; Baran et al. 2012). Sleep inertia may deteriorate arousal and several cognitive performances in the post-awakening period (Wertz et al. 2006) and may thus have influenced our results for the immediate post-sleep measurement. Future studies should thus employ additional tests to preclude such effects. Most importantly, however, we show that sleep after extinction learning during exposure therapy is particularly beneficial for long-term reduction of fear to the phobic stimulus. A possible explanation is that sleep after extinction learning initiates a process of stabilization of the new extinction memory trace, which continues to fully develop over multiple nights. Beneficial effects of sleep on emotional learning have been observed up to 4 years (Wagner et al. 2006). 
In addition, the immediate effect of sleep on generalization of extinction (Pace-Schott et al. 2009) might help to transfer the positive effects of exposure treatment to the real world and 'real' spiders, resulting in most pronounced effects during follow-up testing. Finally, the follow-up testing is not confounded by differences in prior sleep or wakefulness, allowing testing both experimental groups in similar states.

To shed light on the mechanism of action of sleep, we explored the relationship between sleep indices and reductions in fear and cognition. We found a specific relationship between fear and cognition reduction and stage 2 sleep, but not REM sleep. As we examined short naps in this study, the amount of REM sleep was rather small in our sleep group (mean duration $1.5 \mathrm{~min}$ ), which might obscure possible relationships between REM sleep and reductions in fear. While studies support a role for REM sleep in emotional learning processes (Silvestri et al. 2001; Wagner et al. 2001; Silvestri \& Root, 2008; Spoormaker et al. 2011) and have reported correlations with emotional memory measures and REM sleep (Nishida et al. 2009), others have also failed to find such relationships (Baran et al. 2012). An involvement of stage 2 sleep in consolidation processes has been proposed, particularly for simple motor tasks (Walker et al. 2002, 2003; Smith et al. 2004), whereas sleep spindles characterizing stage 2 sleep are believed to play a crucial role in consolidation of several different types of memories during sleep and are supposed to promote plastic changes in cortical networks together with hippocampal memory reactivations (e.g. Rasch et al. 2007; Diekelmann \& Born, 2010; Mölle \& Born, 2011). Thus, further studies are required to specify the role of stage 2 sleep and sleep spindles in memory processes related to fear extinction learning occurring during sleep.

From a clinical perspective, our results indicate that napping after therapy facilitates the effects of VR exposure therapy. This is important, as not all patients benefit from exposure therapy, and for those who benefit, fear often returns following initially successful therapy (Craske \& Mystkowski, 2006). Napping post-therapy may thus be one method for enhancing exposure-based interventions in order to increase response rates. Advising patients to nap following psychotherapy may be beneficial, as novel memories are formed during a session and sleep may increase their consolidation and possibly generalization (Nishida et al. 2009; Pace-Schott, 2012).

Our study is an initial foray into an important clinical application of recent memory research and not without limitations. Future studies will be needed to replicate the beneficial effect of sleep, as well as to extend it to other forms of psychotherapy.
In particular, it may be important to study multiplesession rather than single-session therapies, and to investigate the beneficial effects of sleep on specific therapies for different forms of psychopathology, e.g. depression rather than anxiety disorders. It may also be crucial to clarify the exact mechanisms by which memory consolidation post-therapy takes place, and whether and how this may be interacting with psychopharmacological treatment. This may be particularly important, as we did not assess possible interactions between post-therapy sleep with night sleep following therapy. The present study did not employ physiological measures of arousal during the BAT and future studies should include such measures. Finally, the relatively short sleep period in our study may have precluded longer REM periods. The lack of association between REM sleep and reduction in anxiety may therefore reflect a type II error.

Despite these limitations, our study has a number of strengths. We demonstrated that individuals afflicted with anxiety disorder are able to nap following onesession exposure treatment, and that this short nap benefits emotional memory consolidation post-therapy and thus enhances the effect of psychotherapy. These findings offer an important non-invasive alternative to recent attempts to facilitate therapeutic memory extinction and consolidation processes with pharmacological interventions. Our findings help to understand the memory processes in fear reduction. Given replication with longer follow-up time points and extension to other samples and therapeutic settings, our data may open new avenues for further increasing the effectiveness of psychological therapies for anxiety and possibly other disorders.

\section{Acknowledgements}

We thank Mary Princip and Deborah Widmer for help with data acquisition and conducting VR therapies, and Ursula Kirmse for help with technical setup in the psychophysiology laboratory. The present study was supported by a young investigator grant from the University of Basel (no. DPE2069 to B.K.). B.K. and B.R. are supported by the Swiss National Science Foundation (grant no. PZ00P1-126597 to B.K. and PP00P1-133685 to B.R.).

\section{Declaration of Interest}

None.

\section{References}

Anderer P, Moreau A, Woertz M, Ross M, Gruber G, Parapatics S, Loretz E, Heller E, Schmidt A, Boeck M, 
Moser D, Kloesch G, Saletu B, Saletu-Zyhlarz GM, Danker-Hopfe H, Zeitlhofer J, Dorffner G (2010). Computer-assisted sleep classification according to the standard of the American Academy of Sleep Medicine: validation study of the AASM version of the Somnolyzer $24 \times 7$. Neuropsychobiology 62, 250-264.

APA (1994). Diagnostic and Statistical Manual of Mental Disorders, 4th edn, revised. American Psychiatric Association: Washington, DC.

Arntz A, Lavy E, Van den Berg G, Van Rijsoort S (1993). Negative beliefs of spider phobics: a psychometric evaluation of the Spider Phobia Beliefs Questionnaire. Advances in Behaviour Research and Therapy 15, 257-277.

Baran B, Pace-Schott EF, Ericson C, Spencer RMC (2012). Processing of emotional reactivity and emotional memory over sleep. Journal of Neuroscience 32, 1035-1042.

Beck AT, Steer RA (1987). Beck Depression Inventory: Manual. Psychological Corporation: San Antonio, TX.

Buysse DJ, Reynolds CF, Monk TH, Berman SR, Kupfer DJ (1989). The Pittsburgh Sleep Quality Index: a new instrument for psychiatric practice and research. Psychiatry Research 28, 193-213.

Choy Y, Fyer AJ, Lipsitz JD (2007). Treatment of specific phobia in adults. Clinical Psychology Review 27, 266-286.

Craske MG, Mystkowski JL (2006). Exposure therapy and extinction: clinical studies. In Fear and Learning: Basic Science to Clinical Application (ed. D. H. M. G. Craske and D. Vansteenwegen), pp. 217-234. American Psychological Association: Washington, DC.

De Quervain DJF, Bentz D, Michael T, Bolt OC, Wiederhold BK, Margraf J, Wilhelm FH (2011). Glucocorticoids enhance extinction-based psychotherapy. Proceedings of the National Academy of Sciences USA 108, 6621-6625.

Diekelmann S, Biggel S, Rasch B, Born J (2012). Offline consolidation of memory varies with time in slow wave sleep and can be accelerated by cuing memory reactivations. Neurobiology of Learning and Memory 98, 103-111.

Diekelmann S, Born J (2010). The memory function of sleep. Nature Reviews Neuroscience 11, 114-126.

Diekelmann S, Wilhelm I, Born J (2009). The whats and whens of sleep-dependent memory consolidation. Sleep Medicine Review 13, 309-321.

Emmelkamp PM, Bruynzeel M, Drost L, van der Mast CA (2001). Virtual reality treatment in acrophobia: a comparison with exposure in vivo. Cyberpsychology and Behavior 4, 335-339.

Horne JA, Ostberg O (1976). A self-assessment questionnaire to determine morningness-eveningness in human circadian rhythms. International Journal of Chronobiology 4, 97-110.

Hussaini SA, Bogusch L, Landgraf T, Menzel R (2009). Sleep deprivation affects extinction but not acquisition memory in honeybees. Learning and Memory 16, 698-705.

Johns MW (1994). Sleepiness in different situations measured by the Epworth Sleepiness Scale. Sleep 17, 703-710.

Lahl O, Wispel C, Willigens B, Pietrowsky R (2008). An ultra short episode of sleep is sufficient to promote declarative memory performance. Journal of Sleep Research 17, 3-10.
Magee WJ, Eaton WW, Wittchen HU, McGonagle KA, Kessler RC (1996). Agoraphobia, simple phobia, and social phobia in the National Comorbidity Survey. Archives of General Psychiatry 53, 159-168.

McNally RJ (2007). Mechanisms of exposure therapy: how neuroscience can improve psychological treatments of anxiety disorders. Clinical Psychology Review 27, 750-759.

Mednick S, Nakayama K, Stickgold R (2003).

Sleep-dependent learning: a nap is as good as a night. Nature Neuroscience 6, 697-698.

Mölle M, Born J (2011). Slow oscillations orchestrating fast oscillations and memory consolidation. Progress in Brain Research 193, 93-110.

Mystkowski JL, Craske MG, Echiverri AM (2002). Treatment context and return of fear in spider phobia. Behavior Therapy 33, 399-416.

Mystkowski JL, Craske MG, Echiverri AM, Labus JS (2006). Mental reinstatement of context and return of fear in spider-fearful participants. Behavior Therapy 37, 49-60.

Nishida M, Pearsall J, Buckner RL, Walker MP (2009). REM sleep, prefrontal theta, and the consolidation of human emotional memory. Cerebral Cortex 19, 1158-1166.

Norton PJ, Price EC (2007). A meta-analytic review of adult cognitive-behavioral treatment outcome across the anxiety disorders. Journal of Nervous and Mental Disease 195, 521-531.

Ost LG (1996). One-session group treatment of spider phobia. Behavior Research and Therapy 34, 707-715.

Ost LG, Brandberg M, Alm T (1997). One versus five sessions of exposure in the treatment of flying phobia. Behavior Research and Therapy 35, 987-996.

Pace-Schott E, Verga PW, Bennett TS, Spencer RM (2012). Sleep promoted consolidation and generalizaton of extinction learning in simulated exposure therapy for spider fear. Journal of Psychiatric Research 46, 1036-1044.

Pace-Schott EF, Milad MR, Orr SP, Rauch SL, Stickgold R, Pitman RK (2009). Sleep promotes generalization of extinction of conditioned fear. Sleep 32, 19-26.

Pace-Schott EF, Shepherd E, Spencer RM, Marcello M, Tucker M, Propper RE, Stickgold R (2011). Napping promotes inter-session habituation to emotional stimuli. Neurobiology of Learning and Memory 95, 24-36.

Payne JD, Stickgold R, Swanberg K, Kensinger EA (2008). Sleep preferentially enhances memory for emotional components of scenes. Psychological Science 19, 781-788.

Powers MB, Emmelkamp PM (2008). Virtual reality exposure therapy for anxiety disorders: a meta-analysis. Journal of Anxiety Disorders 22, 561-569.

Price M, Mehta N, Tone EB, Anderson PL (2011). Does engagement with exposure yield better outcomes? Components of presence as a predictor of treatment response for virtual reality exposure therapy for social phobia. Journal of Anxiety Disorders 25, 763-770.

Rasch B, Buchel C, Gais S, Born J (2007). Odor cues during slow-wave sleep prompt declarative memory consolidation. Science 315, 1426-1429.

Ressler KJ, Rothbaum BO, Tannenbaum L, Anderson P, Graap K, Zimand E, Hodges L, Davis M (2004). Cognitive enhancers as adjuncts to psychotherapy: use of 
D-cycloserine in phobic individuals to facilitate extinction of fear. Archives of General Psychiatry 61, 1136-1144.

Ruhmland M, Margraf J (2001). Effectiveness of psychological therapies for specific phobia and obssessive-compulsive disorder: disorder-specific meta-analyses. Verhaltenstherapie 11, 12.

Scheuchenpflug R (2001). Measuring presence in virtual environments. In HCI International (ed. M. J. Smith, G. Salvendy and M. R. Kasdorf), pp. 56-58. Lawrence Erlbaum: Mahwah, NJ.

Schneider S, Margraf J (2006). Diagnostic Interview for Mental Disorders (DIPS). Springer: Berlin.

Silvestri AJ, Root DH (2008). Effects of REM deprivation and an NMDA agonist on the extinction of conditioned fear. Physiology and Behavior 93, 274-281.

Silvestri R, Pace-Schott EF, Gersh T, Stickgold R, Salzman C, Hobson JA (2001). Effects of fluvoxamine and paroxetine on sleep structure in normal subjects: a home-based Nightcap evaluation during drug administration and withdrawal. Journal of Clinical Psychiatry 62, 642-652.

Smith CT, Aubrey JB, Peters KR (2004). Different roles for REM and stage 2 sleep in motor learning: a proposed model. Psychologica Belgica 44, 81-104.

Spoormaker VI, Schröter MS, Andrade KC, Dresler M, Kiem SA, Goya-Maldonado R, Wetter TC, Holsboer F, Sämann PG, Czisch M (2011). Effects of rapid eye movement sleep deprivation on fear extinction recall and prediction error signaling. Human Brain Mapping 33, 2362-2376.

Spoormaker VI, Sturm A, Andrade KC, Schroter MS, Goya-Maldonado R, Holsboer F, Wetter TC, Samann PG, Czisch M (2010). The neural correlates and temporal sequence of the relationship between shock exposure, disturbed sleep and impaired consolidation of fear extinction. Journal of Psychiatric Research 44, 1121-1128.

Stickgold R (2009). How do I remember? Let me count the ways. Sleep Medicine Review 13, 305-308.

Suppiger A, In-Albon T, Herren C, Bader K, Schneider S, Margraf J (2008). Reliabilität des Diagnostischen Interviews bei psychischen Störungen (DIPS für DSM-IV-TR).
[Reliability of the Diagnostic Interview for Mental Disorders (DIPS for DSM-IV-TR).]. Verhaltenstherapie 18, 237-244.

van der Helm E, Gujar N, Nishida M, Walker MP (2011a). Sleep-dependent facilitation of episodic memory details. PLOS ONE 6, e27421.

van der Helm E, Walker MP (2011). Sleep and emotional memory processing. Sleep Medicine Clinics 6, 31-43.

van der Helm E, Yao J, Dutt S, Rao V, Saletin JM, Walker MP (2011b). REM sleep depotentiates amygdala activity to previous emotional experiences. Current Biology 21, 2029-2032.

Wagner U, Gais S, Born J (2001). Emotional memory formation is enhanced across sleep intervals with high amounts of rapid eye movement sleep. Learning and Memory 8, 112-119.

Wagner U, Hallschmid M, Rasch B, Born J (2006). Brief sleep after learning keeps emotional memories alive for years. Biological Psychiatry 60, 788-790.

Walker MP (2008). Sleep-dependent memory processing. Harvard Review of Psychiatry 16, 287-298.

Walker MP (2009). The role of sleep in cognition and emotion. Annals of New York Academy of Science 1156, 168-197.

Walker MP, Brakefield T, Morgan A, Hobson JA, Stickgold R (2002). Practice with sleep makes perfect: sleep-dependent motor skill learning. Neuron 35, 205-211.

Walker MP, Brakefield T, Seidman J, Morgan A, Hobson JA, Stickgold R (2003). Sleep and the time course of motor skill learning. Learning and Memory 10, 275-284.

Walker MP, van der Helm E (2009). Overnight therapy? The role of sleep in emotional brain processing. Psychological Bulletin 135, 731-748.

Wamsley EJ, Stickgold R (2010). Dreaming and offline memory processing. Current Biology 20, R1010-R1013.

Wertz AT, Wright KP, Ronda J M, Czeisler CA (2006). Effects of sleep inertia on cognition. Journal of the American Medical Association 295, 163-164.

Wolpe J, Lazarus AA (1966). Behavior Therapy Techniques. Pergamon Press: Oxford. 